$\underline{\text { Interview }}$

\title{
The Craft of (Queer) Feminism: A Conversation with Neelima P. Aryan, Indian Illustrator and Queer Feminist Woman
}

\author{
E. Dawson Varughese ${ }^{1 *}$
}

Published: April 11, 2020

\section{INTRODUCTION}

E. Dawson Varughese is in conversation with Neelima P. Aryan about her work as an illustrator and specifically as a contributor to Bertonasco, Bartscht and Kuriyan's Drawing the Line: Indian women fight back (2015) in which Neelima's short graphic story 'the prey' features. Together these two women explore ideas of feminism which manifest through creative expression alongside personal experience and endeavour for Neelima as a queer feminist woman living and working in an Indian metropolis in the post millennium era. Specifically, they explore how the text-image interface might capture expressions of feminism different from those expressed in text only and by extension, how this mode of storying facilitates expressions of culturally and socially-situated feminisms, including queer feminisms within the context of urban India.

How did you come to illustration, Neelima? Has it always been part of your life in some way or another?

Drawing has always been a part of my life. My mother is a self-taught artist and in my growing up years, she used to paint a lot. Often my drawings had back-stories and futures that only I knew of. It could be of a woman walking into a supermarket, and if you'd asked me, I'd tell you where she was coming from, that she was going to the supermarket to buy a pencil box and what her plans were after.

Even though I grew up with a little bit of borrowed Archie comics and Tinkle, Balarama and such, it was at 23 when I discovered [the queer USA comic artist] Alison Bechdel that I realised I could do this too, telling stories through illustrations. What Bechdel did with Dykes to Watch Out For (1983-2008) was to show me the possibilities of a queer life, it was an easy overview of 'queer feminism for dummies', and a way to express politics without making it seem boring and inaccessible. I was coming out, I had just discovered a feminist and an LBT support group, and I had a lot to say! I wasn't confident enough though to talk in these forums. I was shy, I believed that my politics was not strong enough, and that I wasn't articulate enough. So, illustrating comic strips became my way of expressing my politics.

I'm interested to talk to you about your part in the Zubaan publication Drawing The Line: Indian women fight back (2015) which features a collection of creative responses to the Nirbhaya case (the Delhi gang rape case) of 2012 and more broadly, responses to the lived experiences of women in India. Could you tell me how you came to contribute 'the prey' to this collection? What was your creative process?

If you look at all the stories in Drawing the Line (2015), most of them are personal narratives of being a woman in an Indian context, some of the stories are direct responses to the 23 year old paramedic's case (Nirbhaya is a euphemism given by the media itself), the stories are also from the artists' own experiences, stories that inspire them, or stories they dream of. Not saying that the Nirbhaya case did not affect us, it did. Rape was suddenly not something that happened only in a socio-economic class that we actively other. It had been part of conversations that we as feminists were having, but suddenly the whole country seemed invested in these conversations. We all seemed to have our own stories to tell, and we told those in Drawing the Line.

${ }^{1}$ Independent Scholar (UK and INDIA) and Senior Fellow at Manipal Centre for Humanities, Manipal Academy of Higher Education (MAHE), Manipal, INDIA

*Corresponding Author: edawsonvarughese@gmail.com 
I was looking for a story to pitch in my application for the Drawing the Line workshop. My mother, an avid Malayalam blogger, read out to me a short story she had written. I felt like I had to make a textless graphic story out of it. So, while I went into the workshop knowing this is the story I will work on, a lot of the other artists developed their narratives through conversations during the course of the workshop.
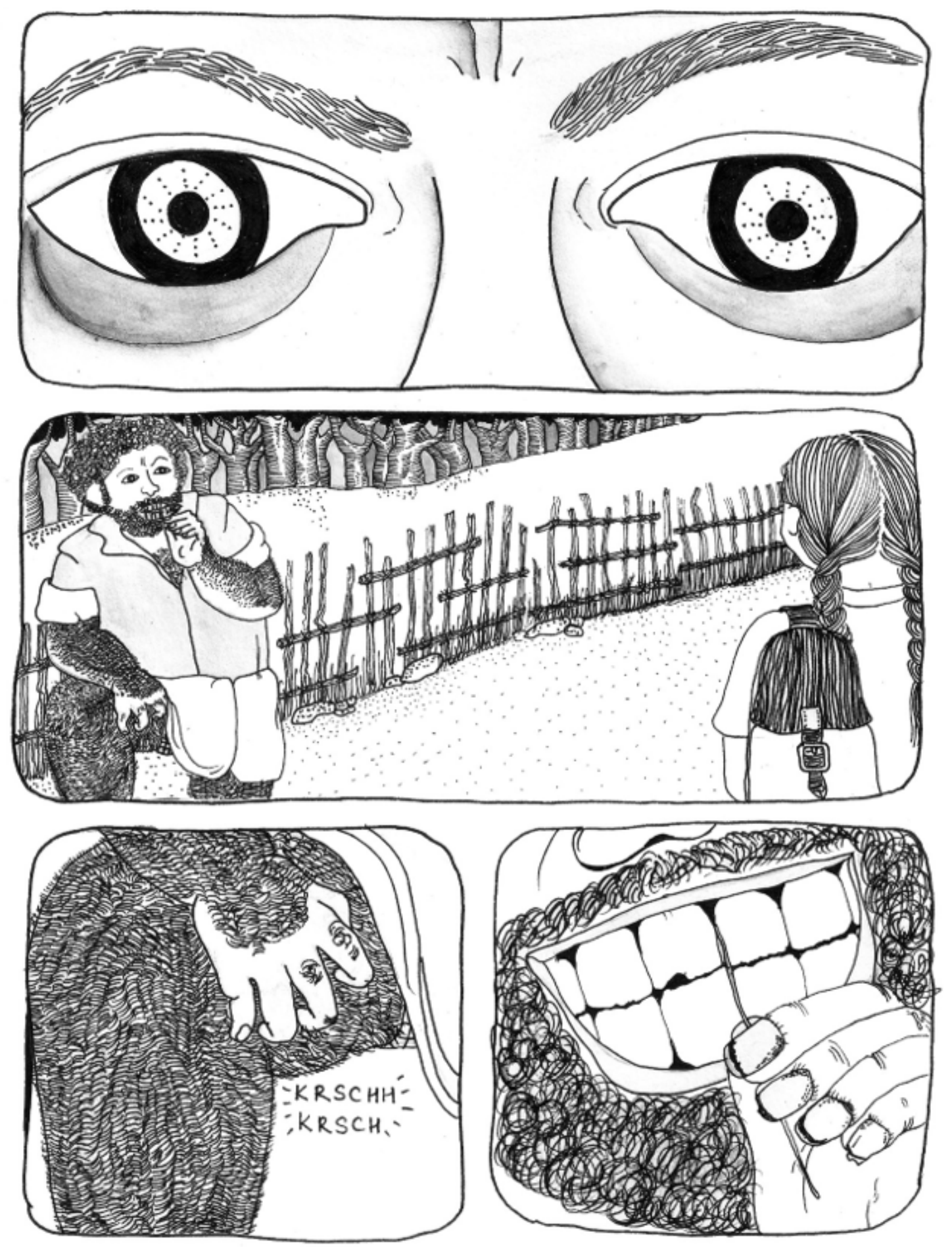

Figure 1. 'Watching' from Drawing the Line. Neelima P. Aryan. 2015. (c) Neelima P. Aryan.

The workshop was a week to 10 days of a seamless ideas exchange between fourteen women and the three facilitators. My story, 'the prey' is set in a village in Kerala and hence that had to come through in the landscape, the setting and the characters. I began drawing the story by visualising the antagonists_-the man and the bird. Once I got the man right, to my satisfaction, the rest of the things automatically fell into place. These images are strongly reminiscent of my childhood. The frame from inside the kitchen, where the mother stands watching the girl, was one of the most satisfying compositions, in terms of the lighting and the setting. It is a typical kitchen in any of the older households in Kerala. Through conversations and shared feedback during the course of the 
workshop, I realised that besides the punch line, it needed some bits of commentary. So, in the end 'the prey' became a graphic short story with text and image.

Working on 'the prey' also became an unexpected collaboration with my mother and her writing. It was her story, and I was giving it a face. Even though I can speak Malayalam fluently, I stumble while reading, and reading literature in Malayalam becomes a whole other feat. Her content is primarily feminist, but also, heavily the musings of a person who restarted with writing as a middle-aged woman trying to find herself a space to express, and explore the world of social media. Occasionally, she reads out to me a poem or two and explains the difficult bits.

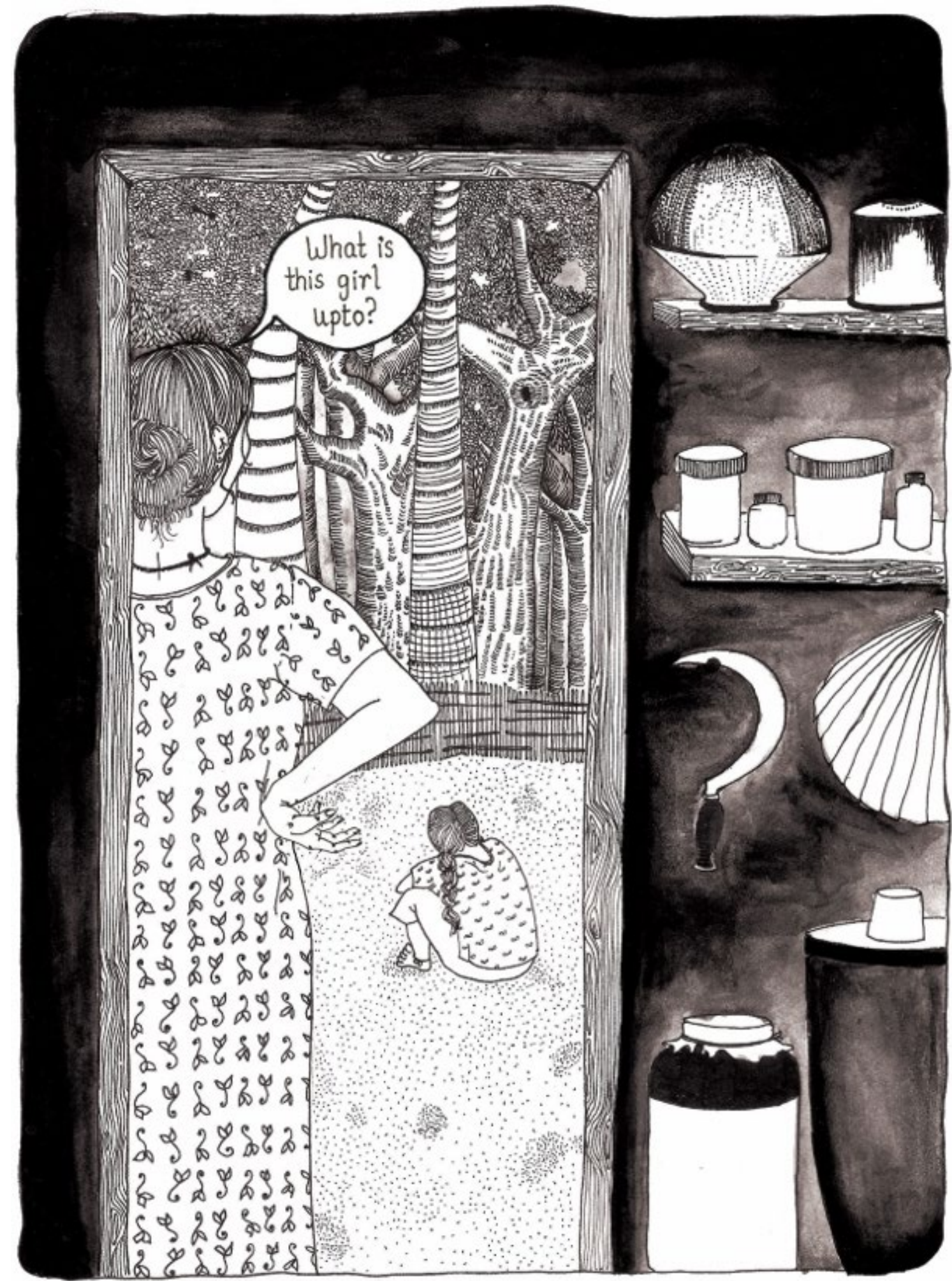

Figure 2. 'What is this girl up to?' from Drawing the Line. Neelima P. Aryan. 2015. (c) Neelima P. Aryan. 
This story, particularly, also uses a certain dialect and language tone that would have gotten lost completely had it been translated into English. However, through a visual translation I could at least attempt to maintain the essence of it in the landscape and setting.

There are many ways in which ideas of 'womanhood' in contemporary India are expressed these days, examples include: autobiography, urban wall art, street demonstrations, creative non-fiction, public lectures, and Instagram posts. What to your mind does the mode of graphic narrative and thus the interface of text and image afford the expression(s) of female and feminist experience specifically? Is there something unique to the mode that allows a certain kind of expression?

There are indeed many ways in which womanhood is represented in Indian culture, and in most of these ways women are somehow still expected to conform. She is a working woman, but she of course is also a mother. There are quicker and simpler ways for her to cook up a meal for her family, but it is her responsibility to make sure even her adult husband is fed healthily, lest he fails to take care of himself. She has to be fair-skinned, energetic, and conscious of her figure, fix the pimples on her face, her heels smooth, and her skin flawless, with a midriff that urges you to reach out and touch. And this is just in advertising. What cinema and tele-serials represent is a whole other universe of submissive misunderstood angels, or conniving go-getter vamps.

I have strangely always drawn women, even as a child. In retrospect, one can maybe joke about my queerness and my affinity to drawing only women. But I never saw women like me. I have always been fat, and people with bodies like me were only used for comic relief, or to represent disgust, or to show how not to be. Even in graphic novels, fat is a representation of a stooge, or someone evil and greedy. Because of what we see, and are used to seeing, we are also used to imagining within those boundaries. When we read a book, most often we are told, in much excruciating detail, what the female protagonist looks like. Sometimes even the male protagonist is not spared. Even if we weren't given these details, we would imagine them to look quite like any of the people we see in the media, those whom we (are supposed to) like and desire. The handsome hero morphs into a lithe Ranveer Singh, or a hunky Gerard Butler. We have our own movie version of the book often running in our imagination. While, graphic stories do not let your imagination wander quite as far because it tethers it to the way the characters are illustrated-I love the fact that I can draw them real if I please! My protagonist can be me, a large queer woman. I can have average and normal looking people in my stories; they need not conform to any norms of beauty or body acceptance or gender. I can push those boundaries and force the reader to engage with a body that might be similar to theirs or one that makes them uncomfortable, one that does not appeal to them. It has been my constant aim to construct and deconstruct representation. I have had women come to me after seeing my graphic erotic story 'Shadow Boxer' (in Meenu and Shruti, 2012) overwhelmed to see a representation of a desirable sexual body as being just like theirs.

Relatedly, might Indian graphic narratives, such as your own work, express culturally and sociallysituated ideas of 'Indian' feminism? You identify as a queer feminist woman and I wonder how your work might (or might not) allow for expressions of this particular identity within the context of post-millennial urban India?

I grew up outside of Kerala. The landscapes I saw there during my vacations while growing up were very different from the more familiar cityscapes. In 'the prey', the setting of the village, of the house, the clothes, the creepy antagonist, those are all visuals one will find in a village or small town in Kerala. The first ever comic I made was about shaving my head in the context of my struggles with my sexuality, but also an assertion of hair as identity, and how an act like a shorn head can also have a religious interpretation. My stories are situated in my identities of being 'Indian and woman', 'Indian and queer', and 'Indian and feminist'; it is a conscious act of expressing my politics.

There are many women artists online for instance, who are using the graphic narrative to talk about not just feminism and queer issues, but also about the larger politics of the country. After all, the rise of a right wing in India is a feminist issue, and this is the right time for such voices to flourish. Artists such as Krutika Susarla and Priya Dali create a lot of online and offline content that are both graphic and political. While personally for me, it feels difficult to find a voice in this social media boom, where content becomes outdated within seconds, and there needs to be a constant content creation for visibility, I also recognise that it is also a great time for graphic content. It holds an important place in putting across information in the simplest and fastest way possible.

Finally, could you say something about the changing scene for 'queer feminists' in India today - how might your own coming-out journey have been shaped by the cultural and societal shifts India has undergone post millennium? Does the future look positive for 'queer feminists'? And how might your own creative work continue to explore and express such identities? 
When I came out in 2003-04, we still hadn't moved onto smart phones. Internet access is what you had at the cyber cafés. I know of people my age, or those who came out at that point, who never searched online about being gay. I chanced upon a film festival that led me to a helpline for lesbian bisexual women, and further introduced me to a feminist and a queer feminist space. I found my little bubble. About 10 years later, Pride in many cities was already four-five years old, 19-year-olds had seen newspaper articles and sought others like them and had come out. And now, the internet is a great space to find support to come out in. Support groups have social media presence and there are more helplines than back in 2003. Can you imagine what it might have been like for someone who came out about 10 years before me? But the truth is that the support group I became a part of turned 20 years old in 2015.

In October 1998, Streesangam, an autonomous voluntary collective of lesbians, started a zine called Scripts. In 1999, I spent a whole summer vacation reading and feverishly taking notes from Ashwini Sukthankar's Facing the Mirror: Lesbian writing from India (1999). (It took me another four years to discover Streesangam and come out of the closet.) Gaysi started as an online blog space for queer women to express themselves, and have been visibly creating a lot of offline buzz in the past couple of years through their zines and zine bazaars. They completed 10 years of publishing in 2018. On October 6, 2018 marking one month of the striking down of the homophobic section 377 of the Indian Penal Code, Scripts magazine, 20 years since its inception, went online.

There cannot be a better time for being a comic creator, in the sense of the exposure one's work can receive. However, it is definitely a really hard battle, considering a lot of it thrives on likes and shares. While the future does look immensely positive to me, I am not sure how much a part of the rat race I see myself. There is growth for me in seeing the kind of work that exists out there, and I mean in the Instagram 'verse for instance. Nevertheless, I worry that I may not be cut out to keep up with the pace of content sharing.

I will hence decide to focus on creating work just for my creative satisfaction and expression, send it out into the 'verse'. What comes of it one shall wait and watch.

\section{Thank you.}

\section{REFERENCES}

Bertonasco, L., Bartscht, L. and Kuriyan, P. (eds). (2015). Drawing the Line: Indian women fight back. New Delhi: Zubaan.

Bechdel, A. (1983-2008). Dykes to Watch out for. New York: Firebrand.

Butalia, P. (2013). Dark Room: Child sexuality in India. London: HarperCollins.

Meenu and Shruti (eds). (2012). Close, Too Close. New Delhi: Westland Tranquebar Publishers.

Sukthankar, A. (ed.). (1999). Facing the Mirror: Lesbian writing from India. New Delhi: Penguin.

Citation: Varughese, E. D. (2020). The Craft of (Queer) Feminism: A Conversation with Neelima P. Aryan, Indian Illustrator and Queer Feminist Woman. Feminist Encounters: A Journal of Critical Studies in Culture and Politics, $4(1), 14$. https://doi.org/10.20897/femenc/7918

Copyright (C) 2020 by Author/s and Licensed by Lectito BV, Netherlands. This is an open access article distributed under the Creative Commons Attribution License which permits unrestricted use, distribution, and reproduction in any medium, provided the original work is properly cited. 